\title{
Characteristics of patients with low-trauma vertebral fractures in the United Arab Emirates: a descriptive multi- center analysis
}

\author{
Eiman Alseddeeqi ${ }^{1)}$, Nihal Bashir ${ }^{2)}$, Khaled F. AlAlii) and Luai A. Ahmed ${ }^{4)}$ \\ 1) Division of Endocrinology, Sheikh Khalifa Medical City, Abu Dhabi, United Arab Emirates \\ 2) Division of Internal Medicine, Sheikh Khalifa Medical City, Abu Dhabi, United Arab Emirates \\ 3) Division of Neurosurgery, Zayed Military Hospital, Abu Dhabi, United Arab Emirates \\ 4) Institute of Public Health, College of Medicine and Health Sciences, United Arab Emirates University, Al Ain, United Arab \\ Emirates
}

\begin{abstract}
Vertebral fracture is the most common type of osteoporotic fracture. However, the prevalence of osteoporosis and osteoporotic vertebral fractures were not explored previously in the United Arab Emirates (UAE). This study aims to describe for the first time the demographic and morphological characteristics of patients with fragility vertebral fractures in the UAE through a retrospective review of the medical records of patients with low-trauma vertebral fractures who visited two tertiary centers during 2011-2016. The sex, age at the time of fracture, nationality, body mass index (BMI), and anatomical fracture location were recorded for each patient. Overall, 143 subjects were diagnosed with low-trauma vertebral fractures in the Emirate of Abu Dhabi during 2011-2016. Of these, 98 were women (68.5\%) and 45 were men (31.5\%). The overall mean patient age at diagnosis was 62.5 years, and almost half were younger than 65 years. Approximately $60 \%$ of the patients were UAE nationals. Fifty-one patients (36.7\%) were obese (mean BMI: $35.3 \mathrm{~kg} / \mathrm{m}^{2}$ ), and women with vertebral fractures had a significantly higher mean BMI compared with men $(p=0.041)$. Nearly $40 \%$ of men had a normal BMI, compared with $20 \%$ of women. Most fractures were compression fractures (77.6\%) in the thoracolumbar transition region. In conclusion, patients with fragility vertebral fractures were predominantly female and tended to be overweight or obese, although male patients tended to have a lower BMI than female patients.
\end{abstract}

Key words: Low-trauma, Osteoporosis, Vertebral fracture, Body mass index, Fragility fracture

OSTEOPOROTIC vertebral fractures are the most common type of osteoporotic fracture and most frequently occur at the thoracolumbar junction [1-3]. These fractures cause significant morbidity, such as debilitating back pain, which leads to a decreased functional capacity and deconditioning [4-7]. Such fractures are also associated with mortality [8] and predict the risk of subsequent vertebral fracture $[9,10]$. However, osteoporotic vertebral fractures are underdiagnosed [11, 12].

Still, many factors known to associate with sustaining fragility vertebral fractures have been identified, including age, ethnicity, post-menopausal status, body mass

Submitted Jan. 17, 2020; Accepted Mar. 7, 2020 as EJ20-0013

Released online in J-STAGE as advance publication Apr. 2, 2020

Correspondence to: Eiman Alseddeeqi, Division of Endocrinology, Sheikh Khalifa Medical City, P.O. Box 51900, Abu Dhabi, United Arab Emirates.

E-mail: ealseddeeqi@seha.ae

Abbreviations: UAE, United Arab Emirates; BMI, body mass index; CT, computed topography; BMD, bone mineral density. index (BMI), and lifestyle practices [13-18].

Osteoporosis is a global health problem. In the Middle East region, osteoporosis and related fractures are considered an emerging health problem because of population aging and the widespread adoption of unhealthy lifestyles, high BMI levels, high rates of vitamin D deficiency, and other risk factors for osteoporosis [19]. Although no official epidemiological data on the burden of osteoporosis in the United Arab Emirates (UAE) have been gathered, regional demographic similarities suggest that the prevalence is likely similar to the rates of 30.549.6\% reported in Saudi Arabia [20]. Currently, there is a dearth of research that has addressed the burden of osteoporotic vertebral fractures in the UAE. This study aims to describe for the first time the demographic and morphological characteristics of patients with fragility vertebral fractures in the UAE. 


\section{Materials and Methods}

\section{Study settings and participants}

This was a retrospective review of the medical records of patients with low-trauma vertebral fractures who visited two tertiary centers in the Emirate of Abu Dhabi during 2011-2016. The relevant ICD-10 codes for vertebral fracture diagnoses were used to search and identify patients with vertebral fractures in the electronic medical records. All diagnoses of vertebral fracture were made by a certified radiologist. Vertebral fractures were confirmed using either plain spinal-view X-rays or vertebral computed tomography (CT) scans and the Denis scale.

All patients older than 17 years who had been diagnosed with vertebral fragility fractures within the study period were identified. The initial search identified 1,134 patients, of whom 1,129 and 47 had available X-ray and CT scan data, respectively (these groups overlapped), to confirm the vertebral fractures. However, confirmatory images were not available for five patients, and these cases were excluded from the study. After reviewing the records of the remaining 1,129 patients, an additional 986 were excluded because they had traumatic vertebral fractures due to motor vehicle crashes and falls from a height $(>2 \mathrm{~m})$. Patients with secondary causes of osteoporosis, such as rheumatological diseases, glucocorticoid use, and malignancy, were also excluded from the study. Finally, one case of incidental fracture was excluded because the date of fracture was unknown. The final number of patients included in this study was 143. This study was approved by the ethical review board of this institution (REC-15.06.2015 [RS-371]) and was conducted in accordance with the Declaration of Helsinki.

\section{Study variables}

Information about each patient's sex, age at the time of fracture, nationality, BMI within approximately 6 months of the fracture event, and the anatomical fracture location were extracted from the medical records. Age was categorized into three groups: $<40,40-64$, and $\geq 65$ years. Ethnicity was classified as UAE National, Arab, Asian, African, and Caucasian. BMI $\left(\mathrm{kg} / \mathrm{m}^{2}\right)$ was calculated as the weight $(\mathrm{kg}) /$ height $(\mathrm{m})^{2}$ and categorized as follows: underweight $\left(<20 \mathrm{~kg} / \mathrm{m}^{2}\right)$, normal (20 to $<25 \mathrm{~kg} / \mathrm{m}^{2}$ ), overweight ( 25 to $<30 \mathrm{~kg} / \mathrm{m}^{2}$ ), and obese $\left(\geq 30 \mathrm{~kg} / \mathrm{m}^{2}\right)$. The exact anatomical locations of the vertebral fractures and the reported type (compression, wedge, and burst) were extracted. The fracture burden was calculated as the number of involved vertebrae per patient.

\section{Statistical analysis}

Categorical data are expressed as numbers and percentages. Continuous data are reported as means and stand- ard deviations. The chi-squared or Fisher's test was used to determine the statistical significance of differences between proportions, and Student's $t$-test was used to compare differences in mean values. Stata 15 (StataCorp. 2017. Stata Statistical Software: Release 15. StataCorp LLC, College Station, TX, USA) was used to perform the analysis. The significance level of the statistical tests was set at $5 \%$.

\section{Results}

A total of 1,129 subjects were diagnosed with vertebral fractures in the two participating tertiary centers in the Emirate of Abu Dhabi during 2011-2016. Of these, 143 were diagnosed with low-trauma vertebral fractures. Table 1 presents the general and fracture characteristics of the low-trauma vertebral fractures patients. 98 patients were female $(68.5 \%)$ and 45 were male $(31.5 \%)$. The overall mean age at diagnosis was 62.5 years. There were no statistically significant differences in mean age between women and men ( $p=0.207)$. In contrast, women with vertebral fractures had a statistically significant higher mean BMI than their male counterparts ( $p=$ 0.041 ), although there were no significant differences in the proportions of BMI categories between women and men $(p=0.174)$. Approximately $60 \%$ of the patients were UAE Nationals. Most of the fractures were compression fractures $(77.6 \%)$ followed by wedge fractures $(18.2 \%)$. There were no statistically significant differences in fracture types or numbers between women and men ( $p=0.718$ and 0.785 , respectively).

A total of 189 vertebrae were affected by fracture among the 143 patients. Of these, 126 and 63 were observed in women and men, respectively. Fig. 1 describes the proportions of the fractured vertebrae. In women, approximately $64 \%$ of the fractures affected the T12 (20.6\%), L1 (28.6\%), and L2 (14.3\%) vertebrae (Fig. 1). In men, approximately $60 \%$ of the fractures affected the T12 (28.6\%), L1 (17.5\%), and L2 (14.3\%) vertebrae.

Valid BMI measurements were available for only 139 of 143 patients. The patients' characteristics are presented according to BMI category in Table 2. Approximately $37 \%$ of patients $(n=51)$ were obese; these patients had a mean BMI of $35.3 \mathrm{~kg} / \mathrm{m}^{2}$ and a mean age of 63.3 years. Overweight and obese patients were more frequent within each age group. However, there were no statistically significant differences in the frequencies of BMI categories between age groups or between different nationalities, fracture types, or burden types. 
Table 1 General characteristics of 143 patients diagnosed with low-trauma vertebral fractures at two tertiary centers in the Emirate of Abu Dhabi during 2011-2016

\begin{tabular}{|c|c|c|c|c|}
\hline & All patients & Women & Men & $p$-value \\
\hline Number (\%) & $143(100)$ & $98(68.5)$ & $45(31.5)$ & \\
\hline Age (mean (SD)) & $62.5(18.4)$ & $63.3(17.2)$ & $60.6(20.8)$ & 0.207 \\
\hline Age groups & & & & 0.133 \\
\hline$<40$ years & $20(14.0)$ & $11(11.2)$ & $9(20.0)$ & \\
\hline $40-64$ years & $50(35.0)$ & $39(39.8)$ & $11(24.4)$ & \\
\hline$\geq 65$ years & $73(51.0)$ & $48(49.0)$ & $25(55.6)$ & \\
\hline BMI $\left(\mathrm{kg} / \mathrm{m}^{2}\right)^{*}($ mean $(\mathrm{SD}))$ & $28.7(7.1)$ & $29.4(7.8)$ & $27.1(5.1)$ & 0.041 \\
\hline BMI groups* & & & & 0.174 \\
\hline Normal $\left(20\right.$ to $\left.<25 \mathrm{~kg} / \mathrm{m}^{2}\right)$ & $45(32.4)$ & $26(27.4)$ & $19(43.2)$ & \\
\hline Overweight ( 25 to $<30 \mathrm{~kg} / \mathrm{m}^{2}$ ) & $43(30.9)$ & $31(32.6)$ & $12(27.3)$ & \\
\hline Obese $\left(\geq 30 \mathrm{~kg} / \mathrm{m}^{2}\right)$ & $51(36.7)$ & $28(40.0)$ & $13(29.5)$ & \\
\hline Nationality/Ethnicity & & & & 0.852 \\
\hline UAE & $85(59.4)$ & $59(60.2)$ & $26(57.8)$ & \\
\hline Arabs & $36(25.2)$ & $24(24.5)$ & $12(26.7)$ & \\
\hline Asians & $12(8.4)$ & $8(8.2)$ & $4(8.9)$ & \\
\hline Africans & $6(4.2)$ & $5(5.1)$ & $1(2.2)$ & \\
\hline Caucasians & $4(2.8)$ & $2(2.0)$ & $2(4.4)$ & \\
\hline Fracture type & & & & 0.718 \\
\hline Compression & $111(77.6)$ & $75(76.5)$ & $36(80.0)$ & \\
\hline Wedge & $26(18.2)$ & $18(18.4)$ & $8(18.8)$ & \\
\hline Burst & $6(4.2)$ & $5(5.1)$ & $1(2.2)$ & \\
\hline Fracture burden (number of fractures per patient) & & & & 0.785 \\
\hline 1 & $116(81.1)$ & $82(83.7)$ & $34(75.6)$ & \\
\hline 2 & $18(12.6)$ & $11(11.2)$ & $7(15.6)$ & \\
\hline 3 & $4(2.8)$ & $2(2.0)$ & $2(4.4)$ & \\
\hline 4 & $2(1.4)$ & $1(1.0)$ & $1(2.2)$ & \\
\hline 5 & $2(1.4)$ & $1(1.0)$ & $1(2.2)$ & \\
\hline 6 & 0 & 0 & 0 & \\
\hline 7 & $1(0.7)$ & $1(1.0)$ & $0(0.0)$ & \\
\hline
\end{tabular}

All values are presented as numbers (\%) unless indicated otherwise.

$*_{n}=139$

BMI, body mass index; SD, standard deviation; UAE, United Arab Emirates

\section{Discussion}

This was the first study to explore the characteristics of patients with low-trauma vertebral fractures in the UAE. Our results demonstrate that most patients with fragility vertebral fractures were obese women with a mean age of 63 years. Compression fractures were the most frequently diagnosed type.

Older age was previously reported to be associated with an increased risk of both osteoporosis and osteoporotic fracture. The mean age of the patients with fracture in this study was younger than the ages reported in other parts of the world [5]. This could be explained by the younger population that resides in the UAE. The majority of UAE residents are younger than 65 years, and almost half of the patients in this study were also younger than 65 years. The high prevalence of overweight, obesity, and vitamin D deficiency $[21,22]$ in this young population would likely have contributed to a higher prevalence of low BMD and related fractures. The age structure of the UAE is expected to change over time consequent to steady increases in life expectancy and a decline in the fertility rate $[23,24]$. These demographic changes are expected to lead to changes in lifestyle practices such as the more widespread adoption of an unhealthy lifestyle and further increases in the BMI, rate of 


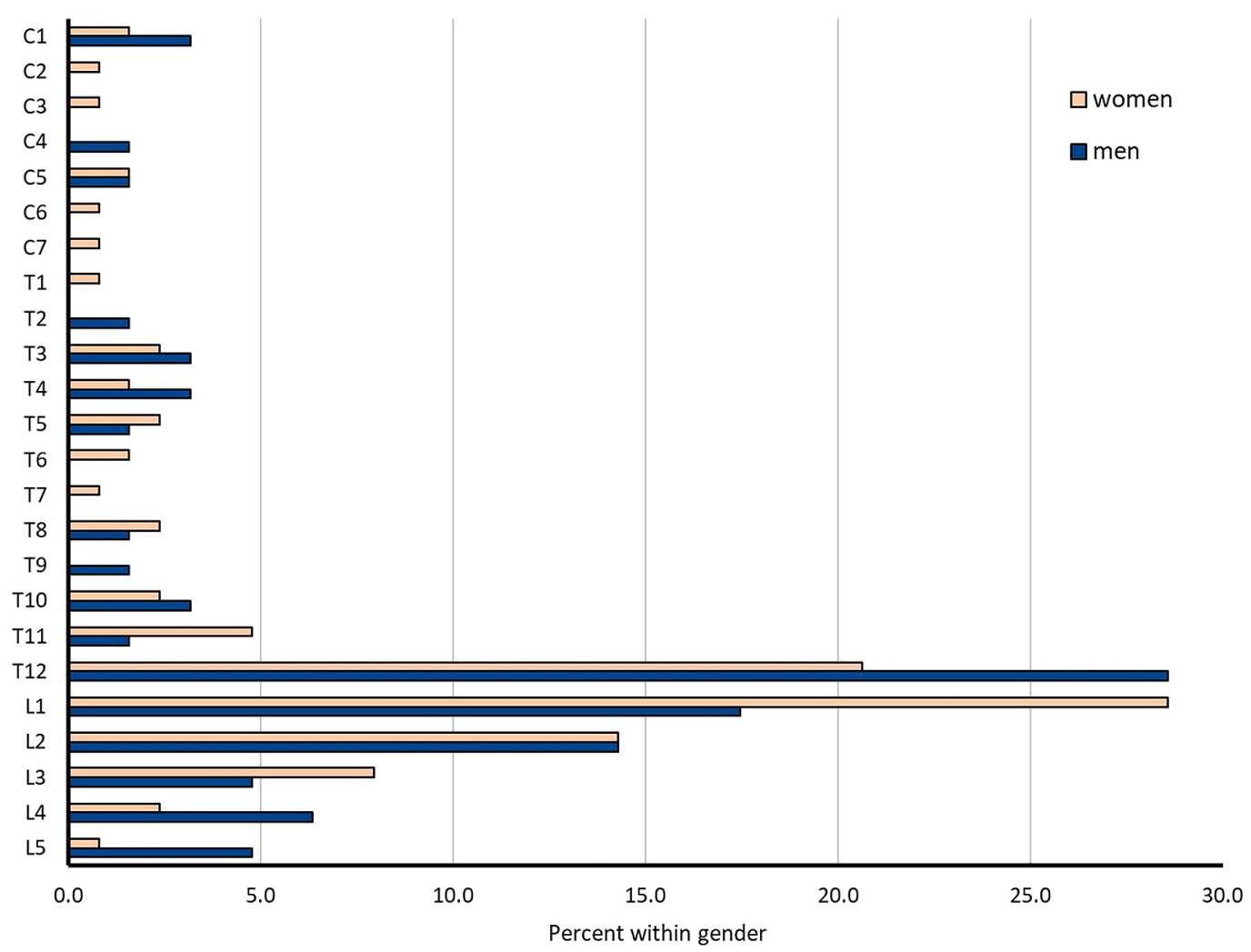

Fig. 1 Proportions of fractured vertebrae by sex in patients with fragility vertebral fractures diagnosed at two tertiary centers in the Emirate of Abu Dhabi during 2011-2016.

vitamin D3 deficiency, and other potential risk factors. These changes will likely increase the burden of osteoporosis and, subsequently, the number and burden of the associated fractures. We further note that the percentage of fragility fractures affecting patients younger than 40 years was $14 \%$, which is non-negligible and certainly concerning, particularly as those patients did not have any of the previously mentioned secondary causes of osteoporosis. Certainly, genetic and dietary factors would be interesting subjects of future studies.

Similar to previous reports [25], most of the patients with vertebral osteoporotic fractures in this study were female. Interestingly, most of our patients with vertebral fractures were also overweight or obese, and women had significantly higher mean BMI levels than men, with a normal BMI recorded for nearly $40 \%$ of men relative to $20 \%$ of women. The high BMI among women supports earlier findings by Pirro et al., who reported a higher BMI level $\left(26.5 \mathrm{~kg} / \mathrm{m}^{2}\right)$ in women with fractures relative to those without fractures [10]. However, a European study observed a negative relationship between BMI and vertebral fractures [26], and a Moroccan study found that vertebral fractures were less prevalent in obese women [27].

\section{Strengths and limitations}

The main strength of this study was the rigorous retrospective chart review design. Moreover, as this study is the first to describe the demographic and morphological characteristics of patients with fragility (i.e., low-trauma) vertebral fractures in the UAE, the results will provide a benchmark for future studies not only in the UAE but also elsewhere in the Middle East, as the populations share similar ethnic backgrounds and lifestyle practices. However, this study was also limited by the small number of included patients and characteristics, the lack of a comparison group, and a lack of BMD measurements. We further note that diabetes mellitus and COPD may also affect bone health, and the inclusion of the true incidence of each condition could have affected the statistical differences between the BMI categories.

\section{Conclusions}

Patients with vertebral fractures in our study were predominantly female, and nearly half were younger than 65 years. Overweight and obesity were highly prevalent among fracture patients, and particularly female patients, who had a higher BMI than their male counterparts. 
Table 2 Characteristics of $139^{*}$ patients diagnosed with low-trauma vertebral fractures at two tertiary centers in the Emirate of Abu Dhabi during 2011-2016 according to BMI category

\begin{tabular}{|c|c|c|c|c|c|}
\hline & $\begin{array}{l}\text { Underweight } \\
\left(<20 \mathrm{~kg} / \mathrm{m}^{2}\right)\end{array}$ & $\begin{array}{c}\text { Normal } \\
\left(20-<25 \mathrm{~kg} / \mathrm{m}^{2}\right)\end{array}$ & $\begin{array}{c}\text { Overweight } \\
\left(25-<30 \mathrm{~kg} / \mathrm{m}^{2}\right)\end{array}$ & $\begin{array}{c}\text { Obese } \\
\left(\geq 30 \mathrm{~kg} / \mathrm{m}^{2}\right)\end{array}$ & $p$-value \\
\hline Number & 9 & 36 & 43 & 51 & \\
\hline BMI, kg/m² (mean (SD)) & $18.0(1.4)$ & $23.4(1.3)$ & $27.5(1.4)$ & $35.3(7.1)$ & \\
\hline Sex & & & & & 0.134 \\
\hline Women & $7(7.4)$ & $19(20.0)$ & $31(32.6)$ & $38(40.0)$ & \\
\hline Men & $2(4.6)$ & $17(38.6)$ & $12(27.3)$ & $13(29.4)$ & \\
\hline Age, years (mean (SD)) & $48.3(23.2)$ & $66.1(19.7)$ & $61.9(17.1)$ & $63.3(16.1)$ & 0.068 \\
\hline Age groups & & & & & 0.169 \\
\hline$<40$ years & $4(21.1)$ & $5(26.3)$ & $4(21.1)$ & $6(31.6)$ & \\
\hline 40-64 years & $3(6.1)$ & $11(22.5)$ & $17(34.7)$ & $18(36.7)$ & \\
\hline$\geq 65$ years & $2(2.8)$ & $20(28.2)$ & $22(31.0)$ & $27(38.0)$ & \\
\hline Nationality/Ethnicity & & & & & 0.061 \\
\hline UAE & $8(9.6)$ & $21(25.3)$ & $24(28.9)$ & $30(36.1)$ & \\
\hline Arabs & $1(2.9)$ & $6(17.1)$ & $10(28.6)$ & $18(51.4)$ & \\
\hline Asians & $0(0.0)$ & $5(45.5)$ & $6(54.5)$ & $0(0.0)$ & \\
\hline Africans & $0(0.0)$ & $1(16.7)$ & $3(50.0)$ & $2(33.3)$ & \\
\hline Caucasians & $0(0.0)$ & $3(75.0)$ & $0(0.0)$ & $1(25.0)$ & \\
\hline Fracture type & & & & & 0.842 \\
\hline Compression & $8(7.3)$ & $29(26.6)$ & $32(29.4)$ & $40(36.7)$ & \\
\hline Wedge & $1(4.0)$ & $6(24.0)$ & $8(32.0)$ & $10(40.0)$ & \\
\hline Burst & $0(0.0)$ & $1(20.0)$ & $3(60.0)$ & $1(20.0)$ & \\
\hline Fracture burden (number of fractures per patient) & & & & & 0.070 \\
\hline 1 & $7(6.3)$ & $26(23.2)$ & $37(33.0)$ & $42(37.5)$ & \\
\hline 2 & $1(5.6)$ & $6(33.3)$ & $4(22.2)$ & $7(38.9)$ & \\
\hline 3 & $0(0.0)$ & $3(75.0)$ & $0(0.0)$ & $1(25.0)$ & \\
\hline 4 & $0(0.0)$ & $0(0.0)$ & $1(50.0)$ & $1(50.0)$ & \\
\hline 5 & $0(0.0)$ & $1(50.0)$ & $1(50.0)$ & $0(0.0)$ & \\
\hline 6 & & 0 & 0 & 0 & \\
\hline 7 & $1(100.0)$ & $0(0.0)$ & $0(0.0)$ & $0(0.0)$ & \\
\hline
\end{tabular}

* A total of 139 of 143 patients with vertebral fracture had a valid BMI.

All values are shown as numbers (\%) unless indicated otherwise.

BMI, body mass index; SD, standard deviation; UAE, United Arab Emirates

\section{Acknowledgments}

Not applicable.

\section{Data Availability}

As the database included in this study is de-identified, it is not available in an open-access repository.

Supporting data can be requested by emailing the corresponding author.

\section{Declarations}

\section{Ethics approval and consent to participate}

Ethical approval was obtained from the Research Ethics Committee at both centers. Consent to participate is not applicable.

\section{Consent for publication}

Not applicable.

\section{Competing interests}

Eiman Alseddeeqi, Nihal Bashir, Khaled Al-Ali, and Luai A. Ahmed declare that they have no competing 
interests.

\section{Disclosure}

\section{Funding}

The study required no funding, and therefore, it did not receive any forms of funding.

\section{Authors' contributions}

All authors (EA, LA, NB, and KA) contributed to the study design. NB and EA accomplished data collection. LA analyzed the material. EA, LA, and KA drafted different parts of the manuscript, and all approved the final version.
This article does not contain any studies with human or animal subjects performed by any of the authors.

\section{Disclosure summary}

Eiman Alseddeeqi, Nihal Bashir, Khaled F. AlAli and Luai A. Ahmed declare that they have no conflicts of interest.

\section{REFERENCES}

1. Rodriguez AJ, Fink HA, Mirigian L, Guanabens N, Eastell $\mathrm{R}$, et al. (2017) Pain, quality of life, and safety outcomes of kyphoplasty for vertebral compression fractures: Report of a Task Force of the American Society for Bone and Mineral Research. J Bone Miner Res 32: 1935-1944.

2. Augat P, Weyand D, Panzer S, Klier T (2010) Osteoporosis prevalence and fracture characteristics in elderly female patients with fractures. Arch Orthop Trauma Surg 130: $1405-1410$

3. Kim DH, Vaccaro AR (2006) Osteoporotic compression fractures of the spine; current options and considerations for treatment. Spine J 6: 479-487.

4. Kanis JA, Cooper C, Rizzoli R, Abrahamsen B, Al-Daghri $\mathrm{NM}$, et al. (2017) Identification and management of patients at increased risk of osteoporotic fracture: outcomes of an ESCEO expert consensus meeting. Osteoporos Int 28: 2023-2034.

5. Ong T, Kantachuvesiri P, Sahota O, Gladman JRF (2018) Characteristics and outcomes of hospitalised patients with vertebral fragility fractures: a systematic review. Age Ageing 47: 17-25.

6. Sun H, Li C (2016) Comparison of unilateral and bilateral percutaneous vertebroplasty for osteoporotic vertebral compression fractures: a systematic review and metaanalysis. J Orthop Surg Res 11: 156.

7. Suzuki N, Ogikubo O, Hansson T (2009) The prognosis for pain, disability, activities of daily living and quality of life after an acute osteoporotic vertebral body fracture: its relation to fracture level, type of fracture and grade of fracture deformation. Eur Spine J 18: 77-88.

8. Ikeda Y, Sudo A, Yamada T, Uchida A (2010) Mortality after vertebral fractures in a Japanese population. J Orthop Surg (Hong Kong) 18: 148-152.

9. Sornay-Rendu E, Munoz F, Garnero P, Duboeuf F, Delmas PD (2005) Identification of osteopenic women at high risk of fracture: the OFELY study. J Bone Miner Res 20: 1813-1819.

10. Pirro M, Fabbriciani G, Leli C, Callarelli L, Manfredelli MR, et al. (2010) High weight or body mass index increase the risk of vertebral fractures in postmenopausal osteoporotic women. J Bone Miner Metab 28: 88-93.

11. Hind K, Pearce M, Birrell F (2017) Total and visceral adiposity are associated with prevalent vertebral fracture in women but not men at age 62 years: the newcastle thousand families study. J Bone Miner Res 32: 1109-1115.

12. Waterloo S, Sogaard AJ, Ahmed LA, Damsgard E, Morseth B, et al. (2013) Vertebral fractures and selfperceived health in elderly women and men in a population-based cross-sectional study: the tromso study 2007-08. BMC Geriatr 13: 102.

13. Svensson HK, Olsson LE, Hansson T, Karlsson J, Hansson-Olofsson E (2017) The effects of personcentered or other supportive interventions in older women with osteoporotic vertebral compression fractures-a systematic review of the literature. Osteoporos Int 28: 25212540 .

14. Bachmann KN, Bruno AG, Bredella MA, Schorr M, Lawson EA, et al. (2016) Vertebral strength and estimated fracture risk across the BMI spectrum in women. $J$ Bone Miner Res 31: 281-288.

15. Kanis JA, Johnell O, Oden A, Dawson A, De Laet C, et al. (2001) Ten year probabilities of osteoporotic fractures according to BMD and diagnostic thresholds. Osteoporos Int 12: 989-995.

16. Li Y, Yan L, Cai S, Wang P, Zhuang H, et al. (2018) The prevalence and under-diagnosis of vertebral fractures on chest radiograph. BMC Musculoskelet Disord 19: 235.

17. Peris P, Guanabens N, Martinez de Osaba MJ, Monegal A, Alvarez L, et al. (2002) Clinical characteristics and etiologic factors of premenopausal osteoporosis in a group of Spanish women. Semin Arthritis Rheum 32: 64-70.

18. Wu F, Mason B, Horne A, et al. (2002) Fractures between the ages of 20 and 50 years increase women's risk of subsequent fractures. Arch Intern Med 162: 33-36.

19. Maalouf G, Gannage-Yared MH, Ezzedine J, Larijani B, Badawi S, et al. (2007) Middle East and North Africa consensus on osteoporosis. J Musculoskelet Neuronal Interact 7: 131-143.

20. Ardawi MS, Maimany AA, Bahksh TM, Nasrat HA, Milaat WA, et al. (2005) Bone mineral density of the spine 
and femur in healthy Saudis. Osteoporos Int 16: 43-55.

21. Radwan H, Ballout RA, Hasan H, Lessan N, Karavetian M, et al. (2018) The epidemiology and economic burden of obesity and related cardiometabolic disorders in the United Arab Emirates: a systematic review and qualitative synthesis. J Obes 2018: 2185942.

22. Sridhar SB, Rao PG, Multani SK, Jain M (2016) Assessment of prevalence of hypovitaminosis D in multiethnic population of the United Arab Emirates. $J$ Adv Pharm Technol Res 7: 48-53.

23. Al-Kuwaiti SJ, Aziz F, Blair I (2015) Frailty in community-dwelling older people in Abu Dhabi, United Arab Emirates: a cross-sectional study. Front Public Health 3: 248.

24. Blair I, Sharif AA (2012) Population structure and the bur- den of disease in the United Arab Emirates. $J$ Epidemiol Glob Health 2: 61-71.

25. Goodwin VA, Hall AJ, Rogers E, Bethel A (2016) Orthotics and taping in the management of vertebral fractures in people with osteoporosis: a systematic review. BMJ Open 6: e010657.

26. Johnell O, O'Neill T, Felsenberg D, Kanis J, Cooper C, et al. (1997) Anthropometric measurements and vertebral deformities. European Vertebral Osteoporosis Study (EVOS) Group. Am J Epidemiol 146: 287-293.

27. El Maghraoui A, Sadni S, El Maataoui A, Majjad A, Rezqi A, et al. (2015) Influence of obesity on vertebral fracture prevalence and vitamin D status in postmenopausal women. Nutr Metab (Lond) 12: 44. 